https://doi.org/10.11646/palaeoentomology.4.3.14

http://zoobank.org/urn:1sid:zoobank.org:pub:78091444-6023-4D8D-9635-66F16F5AA083

\title{
Application of confocal laser scanning microscopy to the study of amber bioinclusions
}

\author{
YAN-ZHE FU ${ }^{1,2, \#, ~ Y A N-D A ~ L I ~}{ }^{1, \#}$, YI-TONG SU ${ }^{1}$, CHEN-YANG CAI ${ }^{1}$ \& DI-YING HUANG ${ }^{1, *}$ \\ ${ }^{1}$ State Key Laboratory of Palaeobiology and Stratigraphy, Center for Excellence in Life and Paleoenvironment, Nanjing Institute of \\ Geology and Palaeontology, Chinese Academy of Sciences, Nanjing 210008, China \\ ${ }^{2}$ University of Chinese Academy of Science, Beijing 100049, China \\ "=yzfu@nigpas.ac.cn; @ ittps://orcid.org/0000-0002-7819-1703 \\ ="ydli@pku.edu.cn; @ http://orcid.org/0000-0002-9439-202X \\ ”ytsu@nigpas.ac.cn; $\odot$ http://orcid.org/0000-0003-0547-0792 \\ "="cycai@nigpas.ac.cn; 이ttp://orcid.org/0000-0002-9283-8323 \\ "'dyhuang@nigpas.ac.cn; @i https://orcid.org/0000-0002-5637-4867 \\ *Corresponding author \\ \#These authors contributed equally to this work
}

\begin{abstract}
Confocal laser scanning microscopy is an essential analytical tool in biological, biomedical, and material sciences, integrating microscope manufacturing technology, optical-electronic technology, and computer technology. In the last decade, confocal laser scanning microscopy has been successfully applied to the study of amber bioinclusions. Enhanced signal to noise ratios, resolution power, capability of optical sectioning, threedimensional reconstruction, and better performance when imaging thicker samples provide a great deal of valuable and detailed morphological information about amber fossils. We briefly discuss the practical applications of CLSM in amber studies and compare it with other imaging methods commonly used in the field, including brightfield microscopy, wide-field fluorescence microscopy, and micro-computed tomography. A general procedure for imaging amber inclusions with CLSM is provided, with a focus on pretreatments and image processing.
\end{abstract}

Keywords: CLSM imaging system, fluorescence, micro$\mathrm{CT}$, fossil, arthropod inclusions

\section{Introduction}

Confocal laser scanning microscopy (CLSM) has been successfully applied in many research fields due to its enhanced signal to noise ratio (SNR) resulting from the effective exclusion of out of focus lights (Halbhuber \& König, 2003; Paddock, 2000; Hovis \& Heuer, 2010). In recent years, CLSM has been found to be useful for the study of amber inclusions, especially dark and well-sclerotised insects and other arthropods. However, applications of this method in amber research are still few and far in between.

In this paper, we briefly introduce the principles of CLSM and its application in amber studies, discuss the advantages of CLSM over other imaging methods, and describe our procedure of imaging amber inclusions with CLSM. We hope that this study will help promote the application of confocal microscopy in the study of amber bioinclusions.

\section{Principles of CLSM}

The imaging procedure used in confocal microscopy differs fundamentally from that of conventional widefield microscopy (Hein et al., 1995; González \& Halpern, 2007; Borlinghaus, 2017). In a confocal microscope (Fig. 1 ), the point source of light and the pinhole in front of the detector lie in optically conjugate focal planes. The laser light source focuses on one point in the focal range of the sample, forming a small illuminated area. Then the fluorescence emission is delivered through a pinhole and imaged on the detector. The pinhole in front of the detector is a key element in confocal imaging, since it acts as a spatial filter, blocking the majority of light from the out-of-focus planes, so that the fluorescent optical signal obtained by the photomultiplier tube detectors (PMT) is all derived from the focal spot of the sample, resulting in great improvements in signal to noise ratios (SNRs) compared to widefield techniques in optical microscopy, especially for thicker samples (Xiao et al., 1999; Paddock, 2000; Borlinghaus, 2017).

Brief history of CLSM in the study of amber inclusions Compared with compression/impression fossils, the 

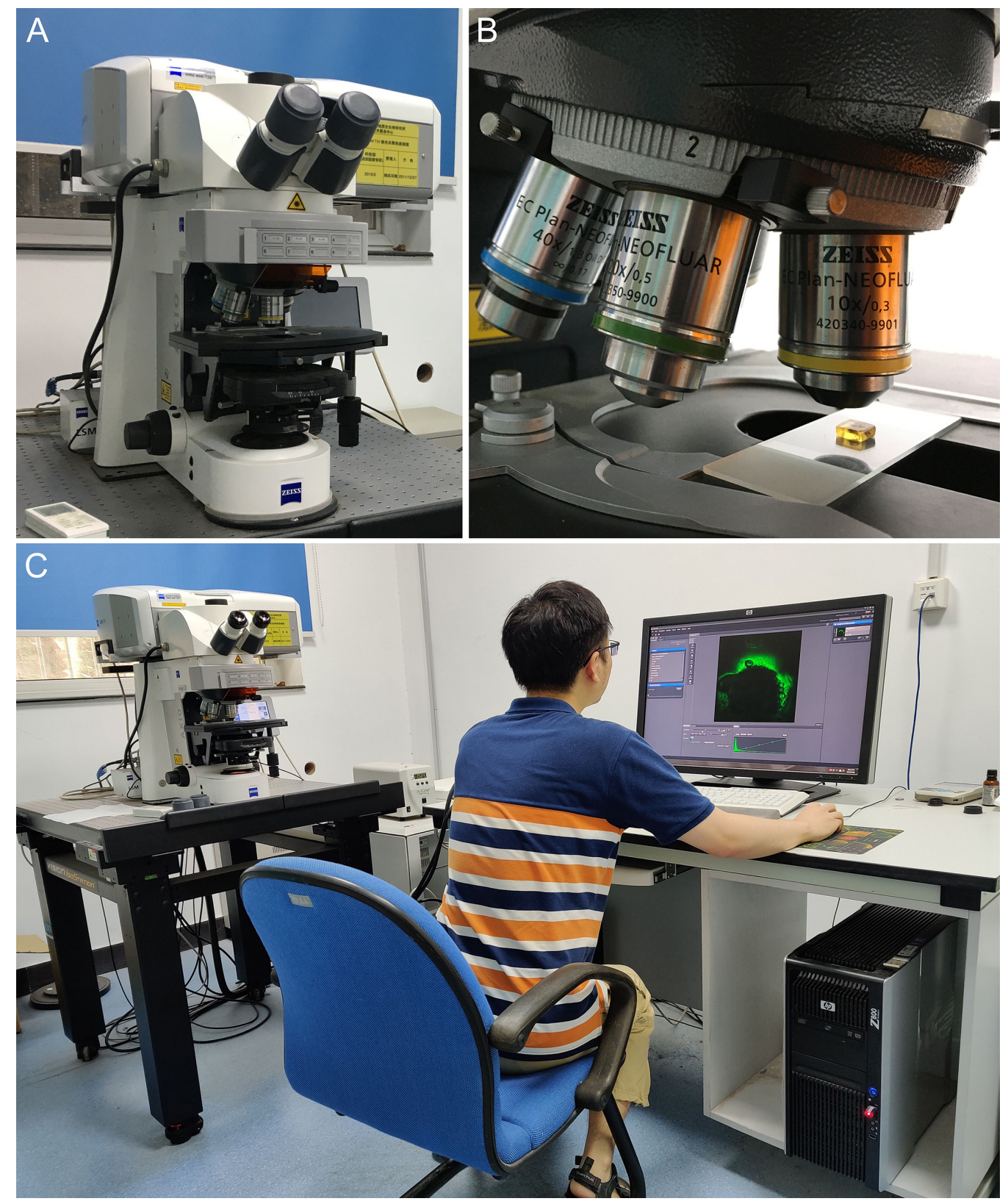

FIGURE 1. Zeiss LSM710 confocal laser scanning microscope system at the Nanjing Institute of Geology and Palaeontology, Chinese Academy of Sciences, Nanjing, China. A, Confocal microscope on an Axio Imager Z2 upright microscope stand. B, Trimmed and polished amber piece on the microscopic slide. C, Dr. Yitong Su ( $3^{\text {rd }}$ author) working with the confocal system.

exceptional three-dimensional preservation of amber fossils usually enables the observation of many valuable morphological details. Therefore, amber inclusions have become crucial for studying the evolution of life and reconstructing palaeoecology and palaeoenvironments. With the development of new imaging techniques, a variety of methods have been applied to the study of amber bioinclusions, including micro-computed tomography (micro-CT), wide-field fluorescence microscopy, and confocal laser scanning microscopy. Böker \& Brocksch (2002) first noticed that confocal microscopy is suitable for studying bioinclusions in Baltic amber and demonstrated the potential for $3 \mathrm{D}$ imaging of minute details using confocal microscopy. Later, a protozoan with fungal hyphae trapped in Spanish amber was examined and a 3D image of partial microcenosis was provided by confocal microscopy (Ascaso et al., 2003, 2005). The use of confocal microscopy for the study of amber bioinclusions has been rapidly developed during the last decade (Clark \& Daly, 2010; Kirejtshuk et al., 2015). Since confocal microscopy enables detailed observation of the morphology of bioinclusions without damaging the sample, and has comparatively better performance on thicker samples, a variety of bioinclusions such as insects, myriapods, plants, fungi, and trichomes from various amber localities (e.g., Spain, Canada, Baltic area, Lebanon, 

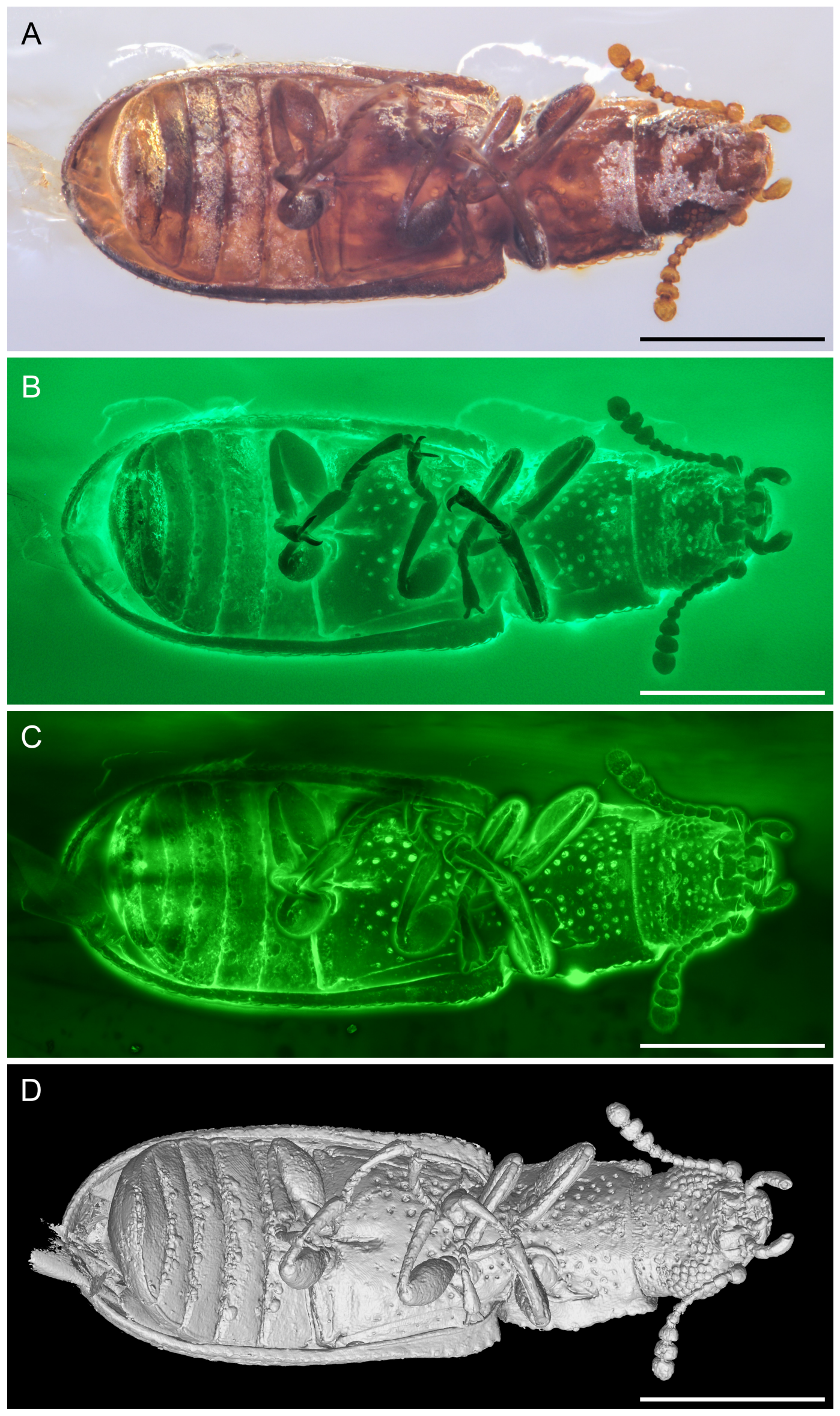

FIGURE 2. A trogossitid beetle (NIGP173910) in Burmese amber under different imaging methods. A, Incident light. B, Widefield fluorescence. C, Confocal microscopy (maximum intensity projection). D, Micro-CT reconstruction. Scale bars: $500 \mu \mathrm{m}$. 

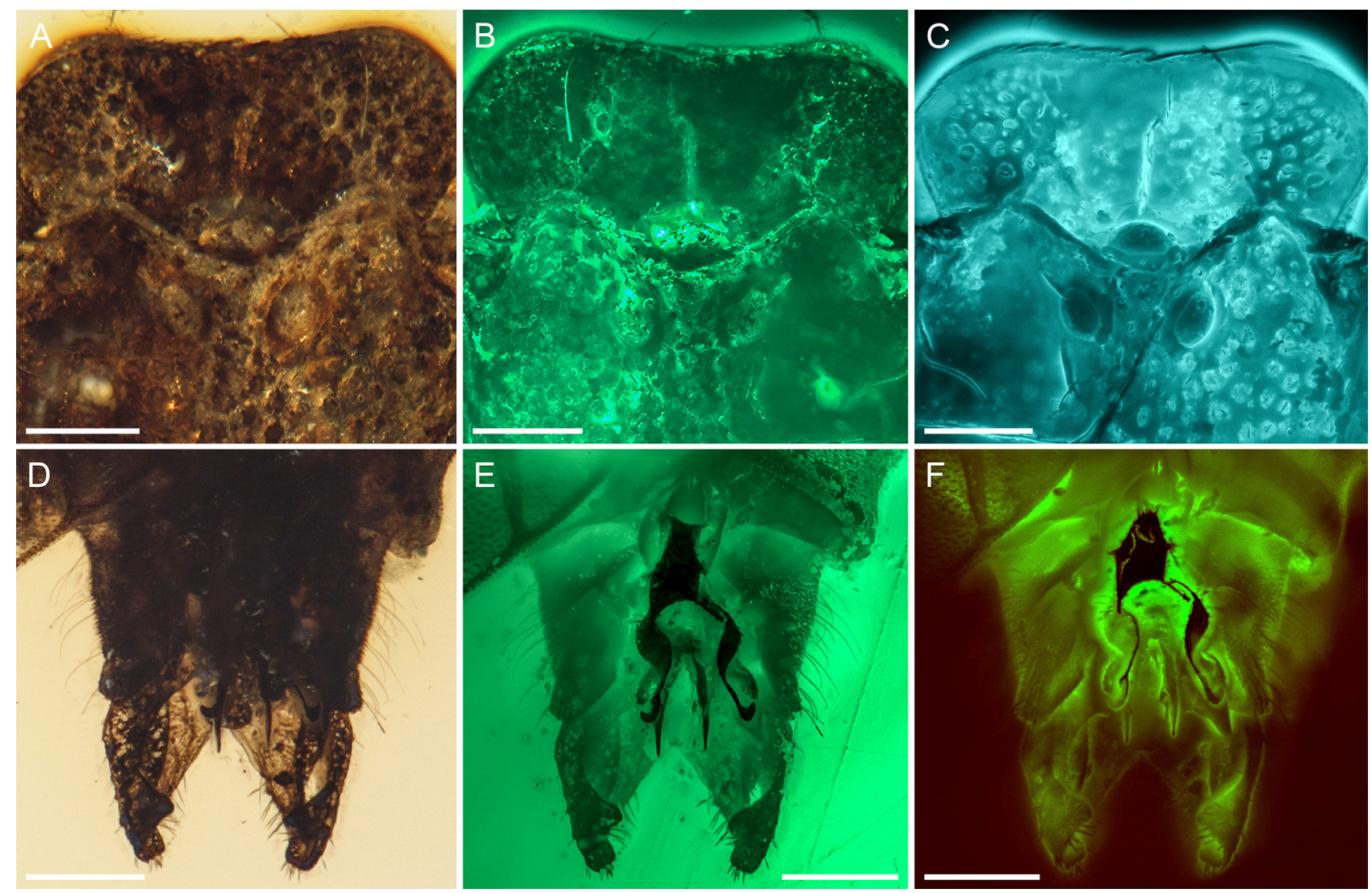

FIGURE 3. Auchenorrhynchan fossils in Burmese amber. A-C, Three ocelli of Minlagerron hongi (NIGP170945). D-F, Pygofer and male genitalia of Cretomultinervis burmensis (NIGP173218). A, D, Incident light; B, E, Wide-field fluorescence; C, F, Confocal microscopy (maximum intensity projection). Scale bars: $200 \mu \mathrm{m}$.

Dominican Republic, and particularly Myanmar) have been analysed using this technique (e.g., Ascaso et al., 2003, 2005; Christiansen \& Nascimbene, 2006; Compton et al., 2010; Clark \& Daly, 2010; Speranza et al., 2010; Bonato et al., 2014; Cai \& Huang, 2014; Kirejtshuk et al., 2015; Arillo et al., 2016).

Christiansen \& Nascimbene (2006) used confocal microscopy to study taxonomically important features of springtails in mid-Cretaceous Burmese amber, which was the first example of the application of confocal technology to the study of Burmese amber bioinclusions. Subsequently, many studies have shown that confocal microscopy is an effective method for reconstructing tiny arthropods (e.g., beetles, myriapods, froghoppers; Bonato et al., 2014; Cai \& Huang, 2014; Zhao et al., 2016; Zhang et al., 2017; Cai et al., 2018, 2019, 2021; Tihelka et al., 2020; Su et al., 2019, 2020; Yin et al., 2019, 2021; Fu et al., 2020, 2021; Liu et al., 2020; Li et al., 2021a, b), spores, and pollen (Prasad et al., 2018; Peyrot et al., 2020; Tihelka et al., 2021) in Burmese amber.

Different imaging methods provide a complementary view of amber fossil morphology

The most common and simplest way to observe fossils in amber is to use a classical optical microscope with incident or transmitted light. However, the boundaries between structures are not always clear with bright-field microscopy (Figs 2A, 3A, D, 4A, D, G, H, 5A), especially for strongly carbonised inclusions (fig. 5C in Tihelka et al., 2020), making it difficult to accurately distinguish between minute structures. In contrast, under a wide-field fluorescence or confocal microscope, the fluorescence emitted around the inclusion's surface clearly illustrates the boundaries of surface structures (Figs 2B, C, 3B, C, E, F, 4B, E, H, K, 5B-E, 6B, D-F; fig. 5B in Tihelka et al., 2020). Nevertheless, conventional imaging with brightfield microscopy has its own irreplaceable advantages. Colour information might be observed under incident light (in some well-preserved specimens; fig. $1 \mathrm{~b}$ in $\mathrm{Li}$ et al., 2021a), while it is completely or almost completely lost with fluorescence (widefield or confocal; fig. $2 \mathrm{~d}$ in Li et al., 2021a) or micro-CT images.

The development of micro-CT techniques offers a great opportunity for palaeontological studies. Using a CT reconstruction, researchers may freely view the fossils from any desired angle (Fig. 2D). It is also possible to virtually remove bubbles covering the fossil inclusions (e.g., Kundrata et al., 2020; Kypke \& Solodovnikov, 2020), or even investigate inclusions in fully opaque amber (Lak et al., 2008). In some exceptionally cases, micro-CT 

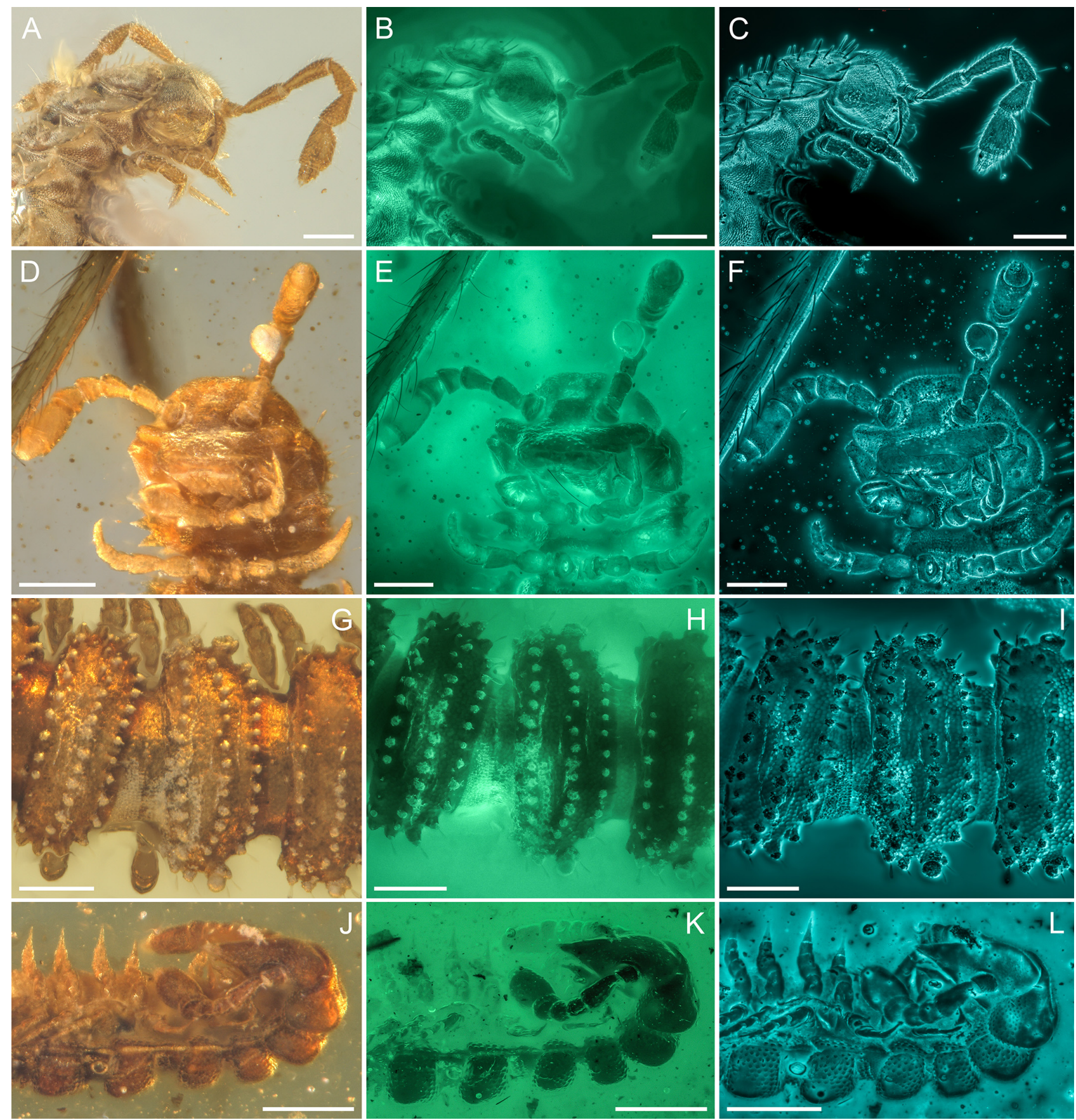

FIGURE 4. Diplopod in Burmese amber under different imaging methods. A-C, Lateral view of the head (NIGP170945). D-F, Ventral view of the head and $1^{\text {st }}, 2^{\text {nd }}$ pairs of appendages. $\mathbf{G}-\mathbf{I}$, Dorsal view of the $8^{\text {th }}$ to $10^{\text {th }}$ segment under incident light. $\mathbf{J}-\mathbf{L}$, Ventrolateral view of the head and the $1^{\text {st }}$ to $6^{\text {th }}$ segment. A, D, G, J, Incident light. B, E, H, K, under widefield fluorescence. C, F, I, L, Confocal microscopy. Scale bars $200 \mu \mathrm{m}$.

may even reveal the internal structures of fossil insects in amber non-destructively (e.g., Van de Kamp, 2014; Li et al., 2021b). However, the quality of micro-CT scanning varies dramatically among different amber inclusions. Some inclusions appear to have poor or no contrast under an X-ray, and therefore cannot be properly imaged (Guo et al., 2016). Besides, even though synchrotron CT may theoretically reach quite high resolutions (Perreau \& Tafforeau, 2011), the resolution of most widely available
micro-CT scanners is still usually lower than optical imaging, especially for larger specimens. Thus, currently optical imaging is still indispensable for the observation of minute structures (e.g., small-sized setae or sensilla) (Heethoff \& Norton, 2009; Robin et al., 2016; Sidorchuk et al., 2018).

Widefield and confocal fluorescence microscopies basically share a similar principle, and therefore generate somewhat similar imaging results (Figs 2B, C, 3E, F). 


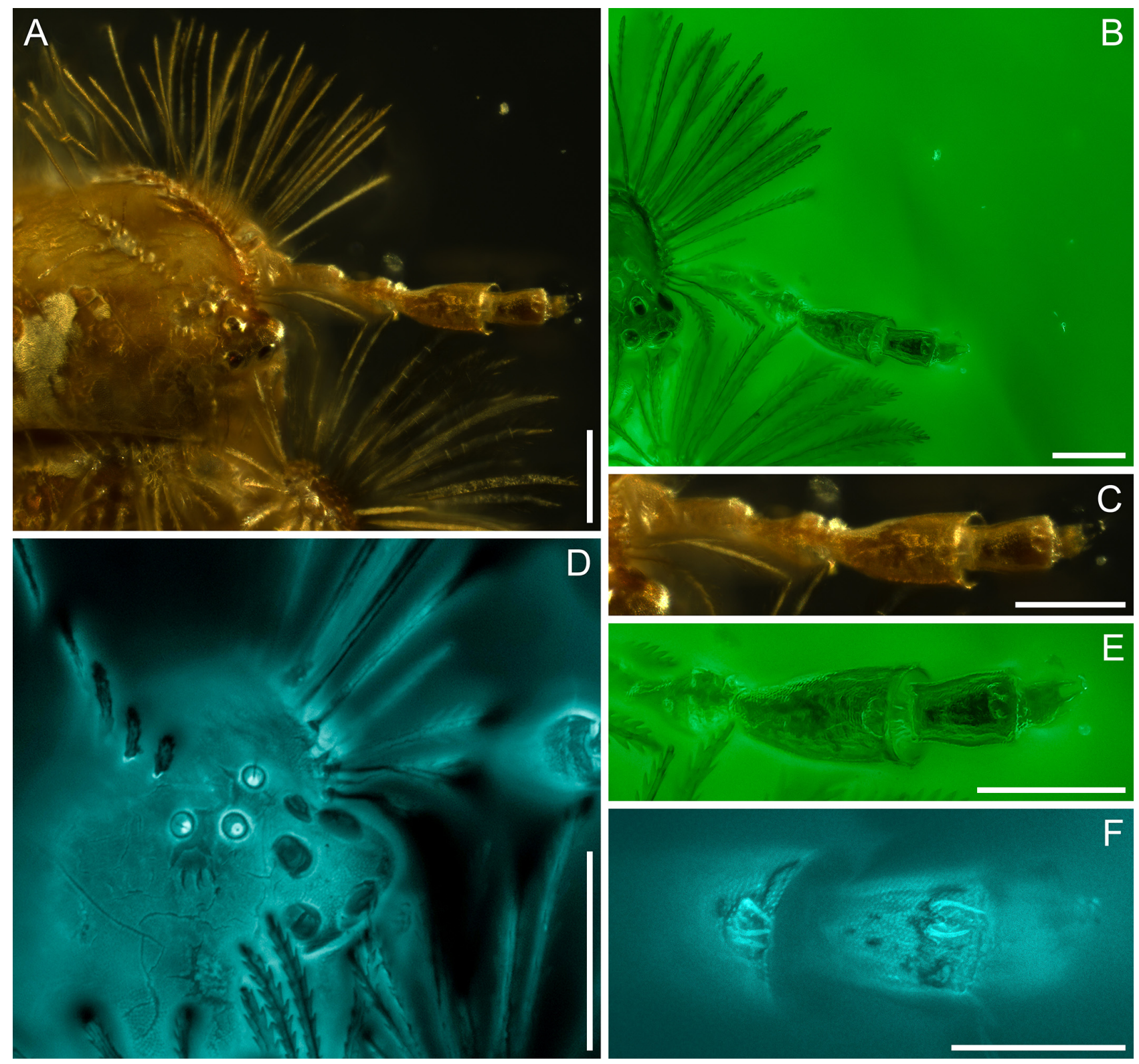

FIGURE 5. Pauropsxenus ordinatus (NGIP168231) in Burmese amber under different imaging methods. A, Trichomes, ommatidia, and basiconic sensilla on antennomeres VI and VII under incident light. B, Same as A, under wide-field fluorescence. $\mathbf{C}$, Enlargement of A, showing details of antenna. D, Trichomes and ommatidia under confocal microscopy. E, Enlargement of B. $\mathbf{F}$, Antennomeres VI and VII under confocal microscopy. Scale bars: $100 \mu \mathrm{m}$ in $\mathbf{A}-\mathbf{E}, 50 \mu \mathrm{m}$ in $\mathbf{F}$.

Although confocal microscopy can generally obtain images with higher quality, wide-field fluorescence microscopy is much less time-consuming. As such, wide-field fluorescence microscopy can be useful for preliminary observations. Besides, since arc-lamps, the light sources for wide-field fluorescence microscopy, provide light with continuous wavelengths, it is much easier to make observations under various excitation wavelengths.

Compared to wide-field fluorescence microscopy, the main advantage of confocal microscopy is its high signal-to-noise ratio. Only fluorescence generated around the surface of the inclusion serves as the desired signal, while fluorescence generated by other parts of the amber matrix is unwanted noise. In wide-field fluorescence microscopy, both signal and background noise are captured by the camera simultaneously, resulting in comparatively low signal-to-noise ratios, especially when the amber layer above the inclusion is thick or strongly fluorescent (fig. 1C, D in Li et al., 2020a). In a confocal system, the out-of-focus background fluorescence produced by the amber matrix is blocked by the pinhole, leading to higher contrast of the structures (Figs 2C, 3C, F, 4C, F, I, L, 5D, E, 6D, F; fig. 4 in Li et al., 2020a). This is useful especially when the amber piece cannot be trimmed further (e.g., when there are long appendages extending into the amber matrix). When a small pinhole size is adopted (e.g., Fig. 5F), confocal microscopy can 

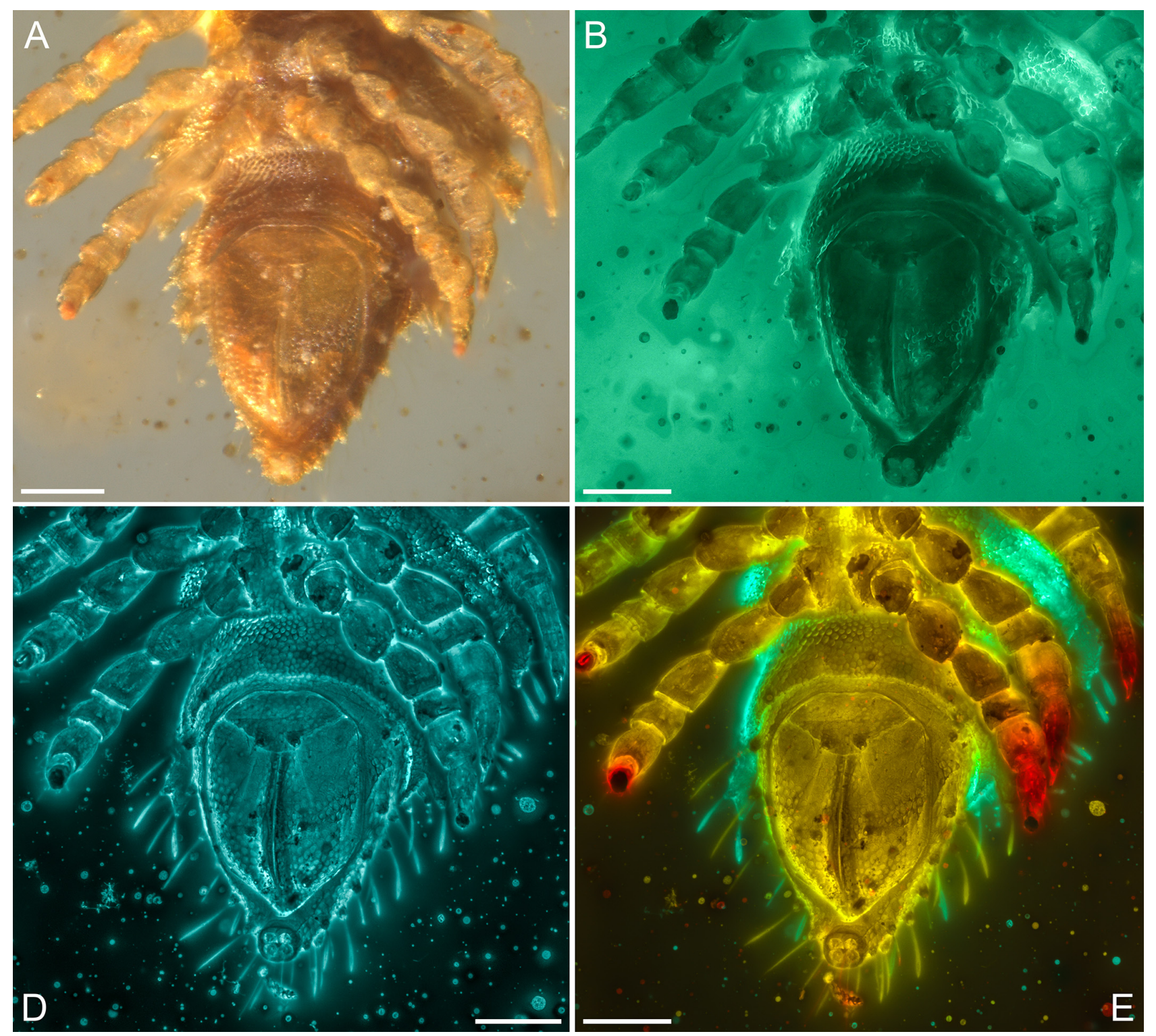

FIGURE 6. Ventral view of the last 2 pairs of appendages and telson of diplopod, under different imaging methods from Burmese amber. A, Incident light. B, Wide-field fluorescence. C, Confocal microscopy. D, Confocal microscopy with depth colour-coding. Scale bars: $100 \mu \mathrm{m}$.

also reach higher resolutions than wide-field microscopy (Cox \& Sheppard, 2004). Besides, the z-stack obtained from a confocal microscope can be easily used to generate a 3D surface reconstruction (e.g., Kirejtshuk et al., 2015). Although it is not impossible to generate a reconstruction from z-stacks obtained by a wide-field microscope, the image processing is much more complicated (Martišek, 2017).

\section{Materials and methods}

\section{Amber materials}

Our research was mainly based on fossil specimens entombed in mid-Cretaceous Burmese amber. However, the technique of CLSM is applicable to studies on any other transparent amber specimens (as discussed in the Introduction). The Burmese amber specimens used as exemplars in this study originated from near Noije Bum $\left(26^{\circ} 20^{\prime} \mathrm{N}, 96^{\circ} 36^{\prime} \mathrm{E}\right)$, Hukawng Valley, Kachin State, northern Myanmar. A diverse group of protists, fungi, plants, invertebrates, and vertebrates have been recorded from the Burmese amber biota (Ross, 2019, 2021). Similar to amber from other localities (e.g., Speranza et al., 2010), Burmese amber varies in optical properties, including colour and transparency, ranging from yellow, orange to reddish brown, and from transparent, semitransparent to opaque (Chen et al., 2018), which could be related to differences in the origin of resin flows in the source plants or chemical microenvironments during resin secretion. 

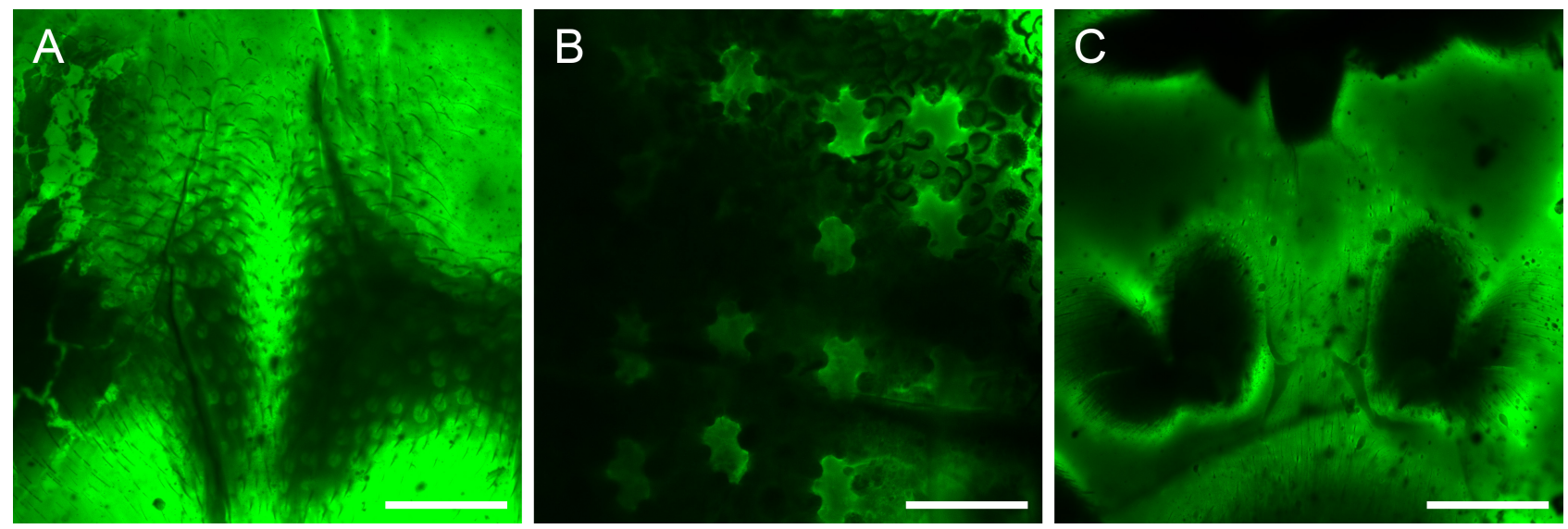

FIGURE 7. Unstacked confocal slices of beetles in the Burmese amber. A, Pronotum of Cretophengodes azari (NIGP173775), showing median lanceolate areola. B, Elytron of Paraodontomma leptocristatum (NIGP174676), showing window punctures and scales. C, Meso-metaventral junction of a psephenid beetle (NIGP173913). Scale bars: $200 \mu \mathrm{m}$.
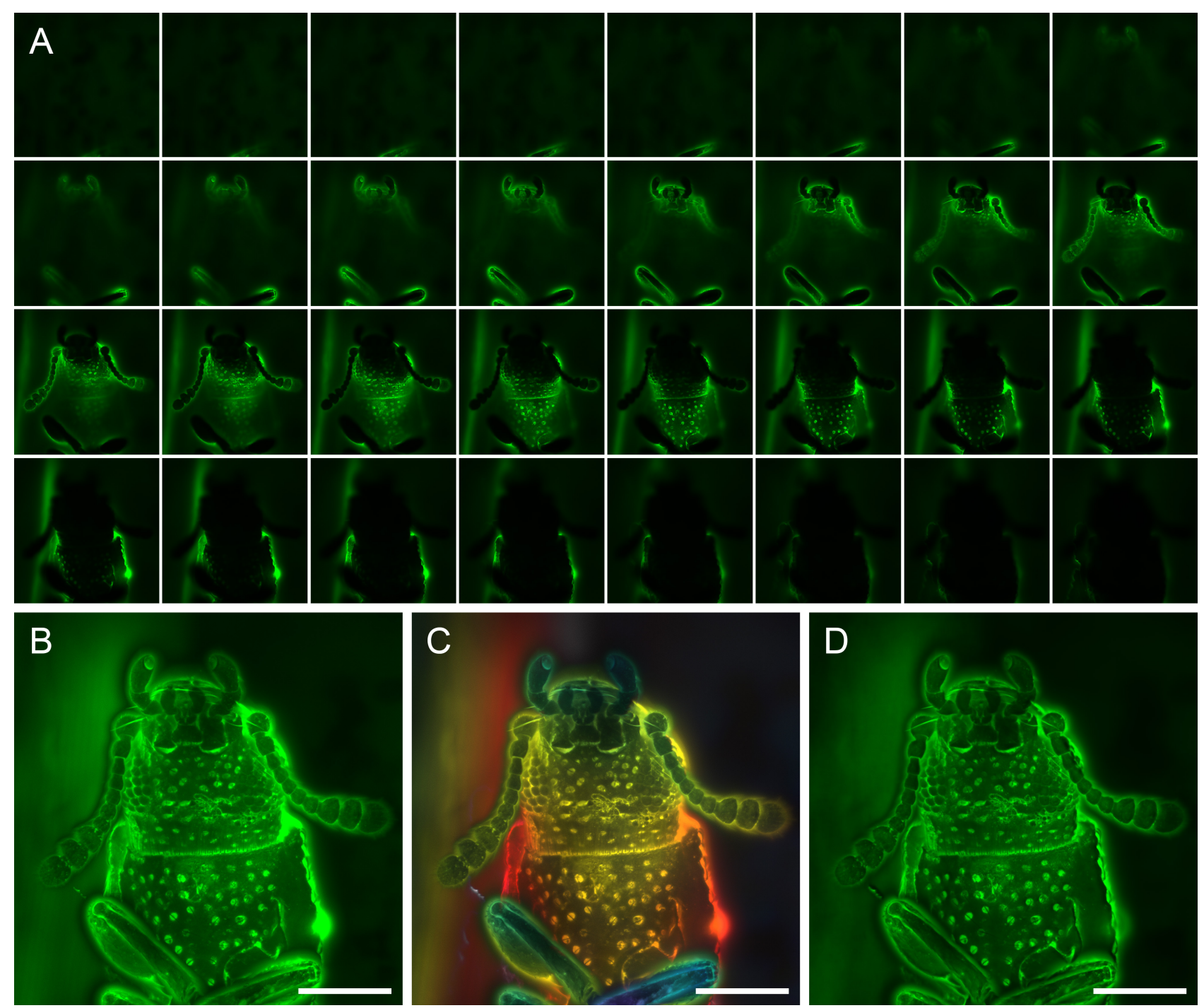

FIGURE 8. Confocal data of a trogossitid beetle (NIGP173910) in Burmese amber. A, Serial confocal slices. B-D, Stacked images by different methods. B, Maximum intensity projection. C, Maximum intensity projection with depth colour coding. D, Weighted average by Helicon Focus. Scale bars: $200 \mu \mathrm{m}$.

Amber specimens illustrated in this study are deposited at the Nanjing Institute of Geology and Palaeontology
(NIGP), Chinese Academy of Sciences (CAS), Nanjing, China. 

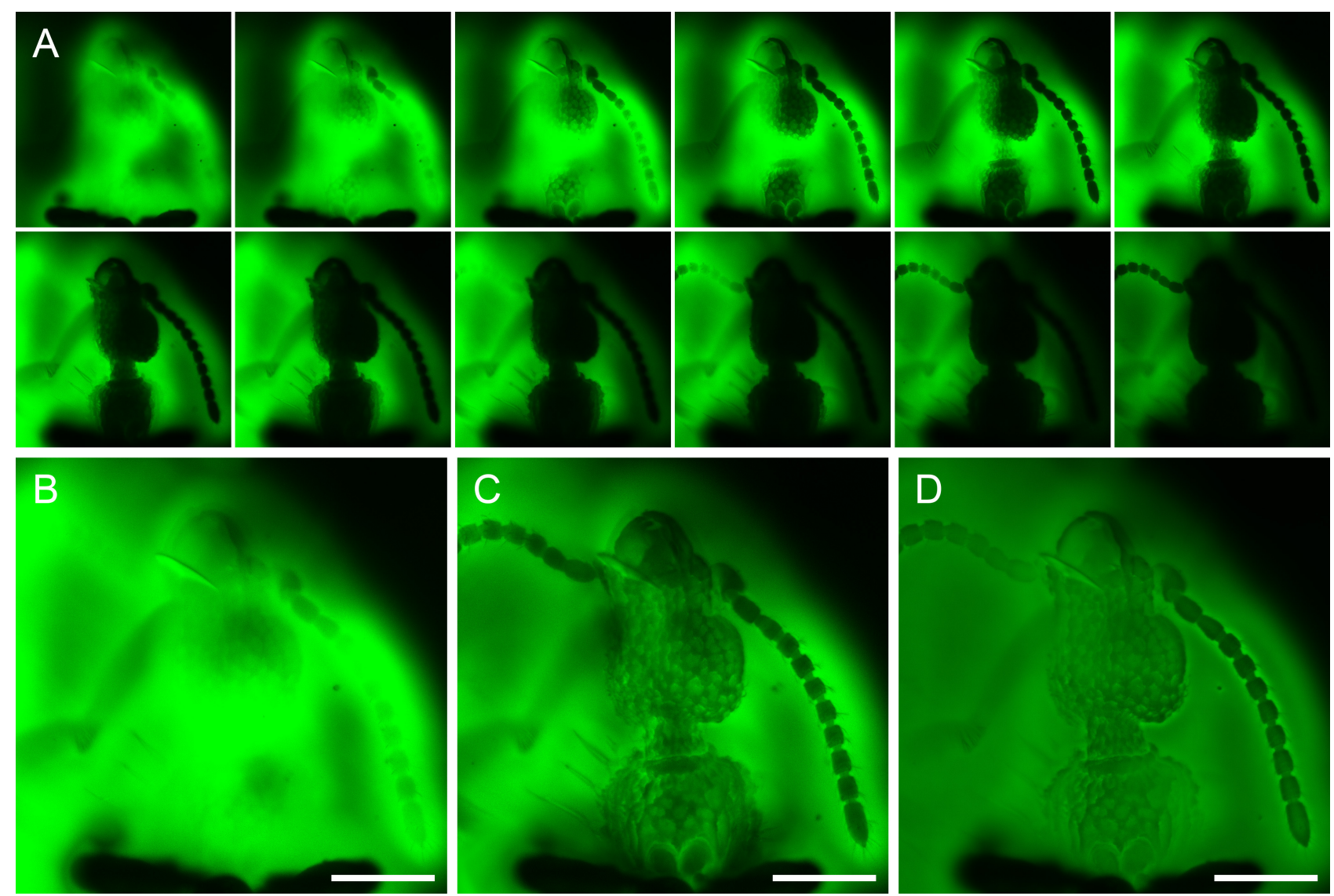

FIGURE 9. Confocal data of Miniomma chenkuni (NIGP173375) in Burmese amber. A, Serial confocal slices. B-D, Stacked images by different methods. B, Maximum intensity projection. C, Manually stacked image. D, Weighted average by Helicon Focus. Scale bars: $200 \mu \mathrm{m}$.

\section{Pretreatments}

Preparation of the sub-millimeter amber pieces is an essential step for obtaining optimal imaging results. The amber pieces containing the inclusion can be cut and shaped manually with a handheld engraving tool and a razor blade, and polished using emery papers of different grit sizes, rare earth polishing powder, and diatomite mud (e.g., Su et al., 2020). The ideal sample should be processed to minimum thickness (generally not exceeding $100 \mu \mathrm{m}$ between the surface of the inclusion and the surface of amber matrix) in order to minimize light scattering. Ideally, the surfaces of the amber piece should be cut and ground flat and parallel to one of the desired planes of observation (Sidorchuk, 2013; Sidorchuk \& Vorontsov, 2018). However, if flat surfaces cannot be achieved, amber pieces can be immersed into mineral oil (e.g., CAS 8020-83-5) during optical imaging to reduce refraction.

The quality of CLSM images is largely dependent on the medium of amber specimens (Kirejtshuk et al., 2015). In some cases, specimens were mounted between two coverslips in a Canada balsam medium to enable clear observation of as many characters as possible, while epoxy resin masks the signal from the inclusion under examination, as noted by Azar et al. (2003) and Kirejtshuk et al. (2015).

\section{Confocal microscopy and imaging}

The following procedure describes the devices and parameters normally used in our research. However, since we didn't test the parameters exhaustively, the procedure described here may not be optimal for every type of amber. The Zeiss LSM710 confocal microscope system at NIGP is installed on an Axio Imager Z2 upright microscope stand with widefield and laser illumination sources (Fig. 2). Normally the amber pieces are observed under an EC Plan-Neofluar 10×/0.30 objective. Burmese amber exhibited a generally ideal signal to background noise ratio when excited with the $488 \mathrm{~nm}$ Argon laser line, and with the emission filter of 493-797 nm. For high-quality images, high laser power and a low scanning speed are desired. The pinhole size is normally set to 1 Airy Unit. A smaller pinhole size might be helpful when observing more detailed structures. The gain can be adjusted to achieve an appropriate exposure. 


\section{Image stacking for confocal data}

In some cases, a single confocal slice is enough to capture minute morphological structures (Fig. 7; fig. 2B-D in Bao et al., 2019). However, to obtain more complete three-dimensional information, a series of slices is usually captured. Therefore, an "extended depth of focus" procedure is required to present three-dimensional confocal data in a two-dimensional plane. The most widely used stacking method for confocal data is the maximum intensity projection (MIP) (Borlinghaus, 2017; Shihavuddin et al., 2017). Maximum intensity projection has been implemented in many programs, including ZEN, the software for manipulating the Zeiss microscope system. This method has been found to be appropriate for many biological samples, where the structures of interest are labeled by a fluorescent tag, because there is little or no background fluorescence emitted. In some amber specimens, fluorescence is produced only around the border between the fossil and the amber (e.g., Fig. 8A; Li et al., 2021c, 2021d). In this case, maximum intensity projection can generate ideal stacking results, since the maximum intensity is obtained exactly on the surface of the fossil (Fig. 8B). In an MIP image, the axial position can also be coded by different colours, so that the information of all three dimensions is retained (Borlinghaus, 2017; Fig. 8C; fig. 7 in Li et al., 2021b). However, for many other amber specimens, there is strong background fluorescence emitted from the amber matrix, which can be even stronger than the fluorescent signal of the fossil surface (e.g., Fig. 9A; Li et al., 2020b, 2021e). In such cases, a maximum intensity projection would be incapable of generating any informative stacking results (Fig. 9B). One possible solution is to manually mark out the insect surface in every slice (e.g., in Adobe Photoshop), and combine them into a single plane (Fig. 9C; fig. 4 in Li et al., 2020a). However, this method is extremely time-consuming, and whether a desired outcome can be achieved is largely dependent on the skill of the operator. The weighted average algorithm (e.g., as implemented in the commercial software Helicon Focus) provides another possible solution. Although the structures may not be as clear as those in manually stacked images, most are still readily identifiable (Fig. 9D). Considering that weighted average is much more time-efficient than manual stacking, it represents a more convenient way to process confocal data, especially when there are a lot of images.

\section{Acknowledgements}

We are grateful to Dr. Yan Fang and Ms. Su-Ping Wu for technical help, and Erik Tihelka for proofreading the paper. This work was supported by the Second
Tibetan Plateau Scientific Expedition and Research (2019QZKK0706), the Strategic Priority Research Program of the Chinese Academy of Sciences (XDB26000000 and XDB18000000), and the National Natural Science Foundation of China (41925008 and 41688103).

\section{References}

Ascaso, C., Wierzchos, J., Corral, J.C., Lopez, C. \& Alonso, J. (2003) New application of light and electron microscopic techniques for the study of microbial inclusions in amber. Journal of Paleontology, 77, 986-996.

https://doi.org/10.1666/0022-3360(2003)077<1182:NAOLAE >2.0.CO;2

Ascaso, C., Wierzchos, J., Speranza, M., Gutiérrez, J.C., González, A.M., de los Ríos, A. \& Alonso, J. (2005) Fossil protists and fungi in amber and rock substrates. Micropaleontology, 51, $59-72$.

https://doi.org/10.2113/51.1.59

Arillo, A., Subías, L.S. \& Sánchez-García, A. (2016) New species of fossil oribatid mites (Acariformes, Oribatida), from the Lower Cretaceous amber of Spain. Cretaceous Research, 63, 68-76.

https://doi.org/10.1016/j.cretres.2016.02.009

Azar, D., Perrichot, V., Neraudeau, D. \& Nel, A. (2003) New psychodid flies from the Cretaceous ambers of Lebanon and France, with a discussion about Eophlebotomus connectens Cockerell, 1920 (Diptera, Psychodidae). Annals of the Entomological Society of America, 96, 117-127. https://doi.org/10.1603/0013-8746(2003)096[0117:NPFTCA]2.0.CO;2

Bao, T., Wang, B., Li, J.G. \& Dilcher, D. (2019) Pollination of Cretaceous flowers. Proceedings of the National Academy of Sciences, USA, 116, 24707-24711. https://doi.org/10.1073/pnas.1916186116

Böker, C. \& Brocksch, D. (2002) Fascinating amber. Carl Zeiss: Innovation, 12, 20-23.

Borlinghaus, R.T. (2017) The white confocal: microscopic optical sectioning in all colours. Springer International Publishing, Cham, 115 pp. https://doi.org/10.1007/978-3-319-55562-1

Bonato, L., Edgecombe, G.D. \& Minelli, A. (2014) Geophilomorph centipedes from the Cretaceous amber of Burma. Palaeontology, 57, 97-110. https://doi.org/10.1111/pala.12051

Cai, C.Y. \& Huang, D.Y. (2014) The oldest micropepline beetle from Cretaceous Burmese amber and its phylogenetic implications (Coleoptera: Staphylinidae). Naturwissenschaften, 101, 813-817. https://doi.org/10.1007/s00114-014-1221-Z

Cai, C.Y., Clarke, D.J., Yin, Z.W, Fu, Y.Z. \& Huang, D.Y. (2019) A specialized prey-capture apparatus in mid-Cretaceous rove beetles. Current Biology, 29, R105-R119. https://doi.org/10.1016/j.cub.2019.01.002 
Cai, C.Y., Thayer, M.K., Newton, A.F., Yin, Z.W. \& Huang, D.Y. (2018) A new genus of dasycerine rove beetles from Upper Cretaceous Burmese amber and its phylogenetic implications (Coleoptera, Staphylinidae). Cretaceous Research, 84, 431436. https://doi.org/10.1016/j.cretres.2017.12.004

Chen, D.J., Yang, J. \& Shao, Y.W. (2019) Amber insects. Chemical Industry Press, Beijing, pp. 1-274 [in Chinese].

Christiansen, K. \& Nascimbene, P. (2006) Collembola (Arthropoda, Hexapoda) from the mid Cretaceous of Myanmar (Burma). Cretaceous Research, 27, 318-363. https://doi.org/10.1016/j.cretres.2005.07.003

Claxton, N.S., Fellers, T.J. \& Davidson, M.W. (2006) Laser scanning confocal microscopy. In: Webster, J.G. (Ed.), Encyclopedia of medical devices and instrumentation. New Jersey, John Wiley \& Sons. pp. 449-477. https://doi.org/10.1002/0471732877.emd291

Clark, N.D.L. \& Daly, C. (2010) Using confocal laser scanning microscopy to image trichome inclusions in amber. Journal of Paleontological Techniques, 8, 1-7.

Cox, G. \& Sheppard, C.J. (2004) Practical limits of resolution in confocal and non-linear microscopy. Microscopy Research and Technique, 63, 18-22. https://doi.org/10.1002/jemt.10423

Cruickshank, R.D. \& Ko, K. (2003) Geology of an amber locality in the Hukawng Valley, northern Myanmar. Journal of Asian Earth Sciences, 21, 441-455. https://doi.org/10.1016/S1367-9120(02)00044-5

Fu, Y.Z., Azar, D. \& Huang, D.Y. (2020) A new species of the extinct family Minlagerrontidae (Insecta: Hemiptera: Cicadomorpha) from mid-Cretaceous Burmese amber. Cretaceous Research, 107,104270 https://doi.org/10.1016/j.cretres.2019.104270

Fu, Y.Z., Szwedo, J. \& Huang, D.Y. (2021) A new sinoalid froghopper in mid-Cretaceous amber from northern Myanmar (Hemiptera, Cicadomorpha, Sinoalidae). Cretaceous Research, 125, 104841. https://doi.org/10.1016/j.cretres.2021.104841

González, S. \& Halpern, A. (2007) Laser-scanning confocal microscopy. In: Soyer, H.P., Argenziano, G., HofmannWellenhof, R. \& Johr, R.H. (Eds), Colour atlas of melanocytic lesions of the skin. Springer, Berlin, Heidelberg, pp. 39-46. https://doi.org/10.1007/978-3-540-35106-1_5

Compton, S.G., Ball, A.D., Collinson, M.E., Hayes, P., Rasnitsyn, A.P. \& Ross, A.J. (2010) Ancient fig wasps indicate at least $37 \mathrm{Myr}$ of stasis in their mutualism with fig trees. Biology Letters, 6, 838-842. https://doi.org/10.1098/rsbl.2010.0389

Guo, M.X., Yang, H.D., Li, G., Tong, Y.-J., Li, S., Lu, Y.Y., Shi, A.M., Wang, B., Zhang, W.W. \& Bai, M. (2016) Morphological identifiability of Burmese amber inclusions under X-rays. Acta Entomologica Sinica, 59, 1013-1020 [In Chinese]. https://doi.org/10.16380/j.kcxb.2016.09.012

Halbhuber, K.J. \& Konig, K. (2003) Modern laser scanning microscopy in biology, biotechnology and medicine. Annals of Anatomy, 185, 1-20.

https://doi.org/10.1016/S0940-9602(03)80002-X

Heethoff, M., Helfen, L. \& Norton, R.A. (2009) Description of Neoliodes dominicus n. sp. (Acari, Oribatida) from Dominican amber, aided by synchrotron X-ray microtomography. Journal of Paleontology, 83, 153-159.

https://doi.org/10.1666/08-101R1.1

Hein, H.J., Czurratis, P., Schroth, D. \& Bernstein, A. (1995) A comparative study of the application of scanning acoustic microscopy and confocal laser scanning microscopy to the structural assessment of human bones. Annals of Anatomy, $177,427-430$.

https://doi.org/10.1016/S0940-9602(11)80149-4

Hovis, D.B. \& Heuer, A.H. (2010) The use of laser scanning confocal microscopy (LSCM) in materials science. Journal of Microscopy, 240, 173-180. https://doi.org/10.1111/j.1365-2818.2010.03399.x

Kirejtshuk, A.G., Chetverikov, P.E. \& Azar, D. (2015) Libanopsinae, new subfamily of the family Sphindidae (Coleoptera, Cucujoidea) from Lower Cretaceous Lebanese amber, with remarks on using confocal microscopy for the study of amber inclusions. Cretaceous Research, 52, 461-479. https://doi.org/10.1016/j.cretres.2014.02.008

Kundrata, R., Bukejs, A., Prosvirov, A.S. \& Hoffmannova, J. (2020) X-ray micro-computed tomography reveals a unique morphology in a new click-beetle (Coleoptera, Elateridae) from the Eocene Baltic amber. Scientific Reports, 10, 20158. https://doi.org/10.1038/s41598-020-76908-3

Kypke, J.L. \& Solodovnikov, A. (2020) Every cloud has a silver lining: X-ray micro-CT reveals Orsunius rove beetle in Rovno amber from a specimen inaccessible to light microscopy. Historical Biology, 32, 940-950. https://doi.org/10.1080/08912963.2018.1558222

Lak, M., Néraudeau, D., Nel, A., Cloetens, P., Perrichot, V. \& Tafforeau, P. (2008) Phase contrast X-ray synchrotron imaging: opening access to fossil inclusions in opaque amber. Microscopy and Microanalysis, 14, 251-259. https://doi.org/10.1017/S1431927608080264

Li, Y.D., Yamamoto, S., Huang, D.Y. \& Cai, C.Y. (2020a) Confocal and micro-CT data of Miniomma chenkuni, holotype, NIGP173375. Zenodo. https://doi.org/10.5281/zenodo.3994920

Li, Y.D., Yamamoto, S., Huang, D.Y. \& Cai, C.Y. (2020b) A miniaturized ommatid beetle in mid-Cretaceous Burmese amber (Coleoptera: Archostemata: Ommatidae). Papéis Avulsos de Zoologia, 60, e20206063. https://doi.org/10.11606/1807-0205/2020.60.63

Li, Y.D., Tihelka, E., Leschen, R.A.B., Yu, Y., Ślipiński, A., Pang, H., Huang, D.Y., Kolibáč, J. \& Cai, C.Y. (2021a) Confocal and micro-CT data of Microtrogossita qizhihaoi, holotype, NIGP173910. Zenodo.

Li, Y.D., Yamamoto, S., Huang, D.Y. \& Cai, C.Y. (2021b) Confocal and micro-CT data of Paraodontomma leptocristatum, 
holotype, NIGP174676. Zenodo.

https://doi.org/10.5281/zenodo.4737033

Li, Y.D., Yamamoto, S., Huang, D.Y. \& Cai, C.Y. (2021c) New species of Paraodontomma from mid-Cretaceous Burmese amber with muscle tissue preservation (Coleoptera: Archostemata: Ommatidae). Papéis Avulsos de Zoologia, 61, e20216153.

https://doi.org/10.11606/1807-0205/2021.61.53

Li, Y.D., Huang, D.Y. \& Cai, C.Y. (2021d) Confocal data of Pseudomataeopsephus burmensis, holotype, NIGP173913. Zenodo.

Liu, Y.M., Hakim, M. \& Huang, D.Y.(2020)First stratiomyomorphan larvae in the mid-Cretaceous amber from Myanmar (Diptera: Brachycera). Cretaceous Research, 106, 104256. https://doi.org/10.1016/j.cretres.2019.104265

Martišek, D. (2017) 3D reconstruction of the surface using a standard camera. Mathematical Problems in Engineering, 2017, 4642397

https://doi.org/10.1155/2017/4642397

Paddock, S.W. (2000) Principles and practices of laser scanning confocal microscopy. Molecular Biotechnology, 16, 127149. https://doi.org/10.1385/MB:16:2:127

Perreau, M. \& Tafforeau, P. (2011) Virtual dissection using phasecontrast X-ray synchrotron microtomography: reducing the gap between fossils and extant species. Systematic Entomology, 36, 573-580. https://doi.org/10.1111/j.1365-3113.2011.00573.x

Peyrot, D., Barrón, E., Pereda-Suberbiola, X. \& Company, J. (2020) Vegetational composition of the Upper Cretaceous vertebrate site of Chera (Valencia, Spain) and its significance in mosaic vegetation from southwestern Europe. Cretaceous Research, 106, 104254.

https://doi.org/10.1016/j.cretres.2019.104254

Prasad, V., Farooqui, A., Murthy, S., Sarate, O.S. \& Bajpai, S. (2018)

Palynological assemblage from the Deccan Volcanic Province, central India: insights into early history of angiosperms and the terminal Cretaceous paleogeography of peninsular India. Cretaceous Research, 86, 186-198.

https://doi.org/10.1016/j.cretres.2018.03.004

Robin, N., Béthoux, O., Sidorchuk, E., Cui, Y., Li, Y., Germain, D., King, A., Berenguer, F. \& Ren, D. (2016) A Carboniferous mite on an insect reveals the antiquity of an inconspicuous interaction. Current Biology, 26, 1376-1382.

https://doi.org/10.1016/j.cub.2016.03.068

Ross, A.J. (2019) Burmese (Myanmar) amber checklist and bibliography 2018. Palaeoentomology, 2 (1), 22-84. https://doi.org/10.11646/palaeoentomology.2.1.5

Ross, A.J. (2021) Supplement to the Burmese (Myanmar) amber checklist and bibliography, 2020. Palaeoentomology, 4 (1), $57-76$.

https://doi.org/10.11646/palaeoentomology.4.1.11

Shihavuddin, A., Basu, S., Rexhepaj, E., Delestro, F., Menezes, N., Sigoillot, S.M., Nery, E.D., Selimi, F, Spassky, N. \&
Genovesio, A. (2017) Smooth 2D manifold extraction from 3D image stack. Nature Communications, 8, 15554.

https://doi.org/10.1038/ncomms15554

Sidorchuk, E.A. (2013) New technique for preparation of smallsized amber samples with application to mites. In: Azar, D., Engel, M.S., Jarzembowski, E., Krogmann, L., Nel, A. \& Santiago-Blay, J.A. (Eds., .Insect Evolution in an amberiferous and stone alphabet. Proceedings of the $6^{\text {th }}$ International Congress on Fossil Insects, Arthropods and Amber. Brill, Leiden-Boston. pp. 189-201.

https://doi.org/10.1163/9789004210714_014

Sidorchuk, E.A. \& Vorontsov, D.D (2018) Preparation of small-sized 3D amber samples: state of the technique. Palaeoentomology, 1 (1), 80-90.

https://doi.org/10.11646/palaeoentomology.1.1.10

Speranza, M., Wierzchos, J., Alonso, J., Bettucci, L., MartínGonzález, A. \& Ascaso, C. (2010) Traditional and new microscopy techniques applied to the study of microscopic fungi included in amber. In: Méndez-Vilas, A. \& Díaz, J. (Eds) Microscopy: science, technology, applications and education. Badajoz, Spain, pp. 1135-1145.

Su, Y.T., Cai, C.Y. \& Huang, D.Y. (2019) Revision of Phryssonotus burmiticus (Diplopoda, Polyxenida, Synxenidae) in midCretaceous amber from Myanmar. Cretaceous Research, 93, 216-224.

https://doi.org/10.1016/j.cretres.2018.09.002

Su, Y.T., Cai, C.Y. \& Huang, D.Y. (2020) Two new species of the bristle millipede genus Pauropsxenus (diplopoda, Polyxenidae) in mid-Cretaceous Burmese amber. Cretaceous Research, 111, 104427.

https://doi.org/10.1016/j.cretres.2020.104427

Tihelka, E., Huang, D.Y. \& Cai, C.C. (2020) New data on Ommatidae (Coleoptera) from mid-Cretaceous Burmese amber. Cretaceous Research, 106, 104253.

https://doi.org/10.1016/j.cretres.2019.104253

Tihelka, E., Li, L.Q., Fu, Y.Z., Su, Y.T., Huang, D.Y. \& Cai, C.Y. (2021) Angiosperm pollinivory in a Cretaceous beetle. Nature Plants, 7, 445-451. https://doi.org/10.1038/s41477-021-00893-2

Van de Kamp, T., Dos Santos Rolo, T., Baumbach, T. \& Krogmann, L. (2014) Scanning the past-synchrotron X-ray microtomography of fossil wasps in amber. Entomologie heute, 26, 151-160.

Xiao, Y.M., Fu, D.L. \& Li, A.S. (1999) Laser scanning confocal microscope (LSCM) and its application in biology. Acta Laser Biology Sinica, 8, 305-311 [in Chinese]. https://doi.org/10.1007/BF02946523

Yin, Z.W., Chandler, D.S. \& Cai, C.Y. (2019) Priscaplectus gen. nov. and two new species in mid-Cretaceous amber from Myanmar (Coleoptera: Staphylinidae: Pselaphinae). Cretaceous Research, 103, 104174. https://doi.org/10.1016/j.cretres.2019.07.004

Yin, Z.W., Lü, L., Yamamoto, S, Thayer, M.K., Newton, A.F. \& Cai, C.Y. (2021) Dasycerinae rove beetles: Cretaceous 
diversification, phylogeny and historical biogeography (Coleoptera: Staphylinidae: Dasycerinae). Cladistics, 37, 185-210.

https://doi.org/10.1111/cla.12430

Zhang, Q.Q., Zhang, J.F. \& Wang, B. (2017) First record of the subfamily Archinemestriinae in the family Nemestrinidae (Diptera: Brachycera) from Upper Cretaceous Burmese amber. Cretaceous Research, 75, 141-145.

https://doi.org/10.1016/j.cretres.2017.03.005

Zhao, X.D, Zhang, Q.Q., Jarzembowski, E.A., Chen, L. \& Wang, B. (2016) A new earwingfly from mid-Cretaceous Burmese amber (Mecoptera: Meropeidae). Cretaceous Research, 66, 136-140.

https://doi.org/10.1016/j.cretres.2016.06.008 